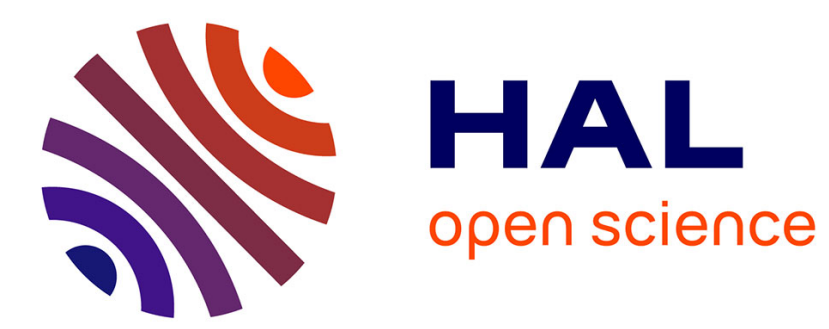

\title{
Anxiety in children with CFS/ME
}

Esther Crawley, Linda Hunt, Paul Stallard

\section{To cite this version:}

Esther Crawley, Linda Hunt, Paul Stallard. Anxiety in children with CFS/ME. European Child and Adolescent Psychiatry, 2009, 18 (11), pp.683-689. 10.1007/s00787-009-0029-4 . hal-00535155

\section{HAL Id: hal-00535155 \\ https://hal.science/hal-00535155}

Submitted on 11 Nov 2010

HAL is a multi-disciplinary open access archive for the deposit and dissemination of scientific research documents, whether they are published or not. The documents may come from teaching and research institutions in France or abroad, or from public or private research centers.
L'archive ouverte pluridisciplinaire HAL, est destinée au dépôt et à la diffusion de documents scientifiques de niveau recherche, publiés ou non, émanant des établissements d'enseignement et de recherche français ou étrangers, des laboratoires publics ou privés. 


\title{
Anxiety in children with $\mathrm{CFS} / \mathrm{ME}$
}

\author{
Esther Crawley $\cdot$ Linda Hunt $\cdot$ Paul Stallard
}

Received: 5 October 2008/Accepted: 1 May 2009/Published online: 19 May 2009

(C) Springer-Verlag 2009

\begin{abstract}
Anxiety symptoms are commonly described in children with chronic fatigue syndrome or myalgic encephalopathy (CFS/ME) but to date there has been little information on the type of anxiety children experience or the relationship between anxiety and school attendance, disability or fatigue. The aim of this study was to first describe the prevalence and type of anxiety symptoms in children with CFS/ME compared with a normal European population, and secondly to investigate the association of anxiety symptoms with age, gender, school attendance, fatigue, and physical function in paediatric CFS/ME. Data were prospectively collected on children and young people with CFS/ME referred to a large specialist CFS/ME service. One hundred and sixty-four children with CFS/ME had complete data for the Spence Children's Anxiety Scale. Teenage girls had the highest rates of total anxiety symptoms with $38 \%$ (95\% CI 27-49) over the cut off (top $10 \%$ of normal European population) and significantly higher rates of symptoms in each subscale. Younger girls were more likely to score over the cut off in separation anxiety
\end{abstract}

\footnotetext{
E. Crawley $(\square)$

Centre of Child and Adolescent Health, Hampton House,

Cotham Hill, Bristol BS6 6JS, UK

e-mail: esther.crawley@bristol.ac.uk

\section{Hunt}

Department of Clinical Sciences at South Bristol, Institute of Child Life and Health, UBHT Education Centre, Upper Maudlin Street, Bristol BS2 8AE, UK

e-mail: L.P.Hunt@bristol.ac.uk

\section{P. Stallard}

Department of Child and Family Psychiatry,

Royal United Hospital, University of Bath,

Combe Park, Bath BA1 3NG, UK

e-mail: p.stallard@bath.ac.uk
}

(37\%, 19-40) and social phobia (39\%, 25-47). There was no evidence of association between total anxiety symptoms and: time at school, time to assessment, pain or age. Associations with fatigue and physical function were attenuated when adjusted for other variables. Although anxiety symptoms are high in CFS/ME, particularly in teenage girls, it does not appear to be associated with school attendance or other measures of disability. Separation anxiety and social phobia were the most clearly elevated in paediatric CFS/ME.

Keywords Anxiety · Paediatric . Chronic fatigue syndrome $\cdot$ ME

\section{Introduction}

Chronic fatigue syndrome or myalgic encephalopathy (CFS/ME) affects between 0.1 and $2 \%$ of children aged under $18[3,9,12,13,17,20]$ and is the most common cause of school absence in the UK [5]. CFS/ME is defined in the Royal College of Paediatrics and Child Health $(\mathrm{RCPCH})$ as "generalised fatigue persisting after routine tests, and investigations have failed to identify an obvious underlying cause" [21]. The National Institute for Health and Clinical Excellence (NICE) recommended in 2007 that a minimum of 3 months of fatigue is required before a diagnosis of CFS/ME is made in children [16].

Anxiety disorders occur frequently in children and young people [4] and anxiety is probably the most common comorbid psychiatric problem in children with CFS/ME. Between 40 and $50 \%$ of children with CFS/ME has been identified with an anxiety disorder using diagnostic interviews or self-completed assessments [6, 19]. Anxiety also appears to be more common in children with CFS/ME when 
compared with children with other long-term conditions, such as juvenile idiopathic arthritis and migraine [18, 23]. However, these findings are limited by small sample sizes and to date it has not been possible to explore potential differences in the way anxiety presents in younger and older children, or whether there are differences in the presentation of boys and girls [1, 10, 19]. Similarly, no studies have investigated the nature of the anxiety and whether specific anxiety symptoms are associated with CFS/ME. The significant school absence seen in CFS/ME raises the possibility of children developing school phobia or, with younger children, increased difficulty separating from their parents [6]. Understanding the specific nature of the anxiety may have treatment implications and indicate whether and which specific anxiety symptoms may require direct intervention.

This paper examines anxiety in a large group of children with CFS/ME, who attended a specialist CFS/ME service. It compares the prevalence of anxiety symptoms using the Spence Children's Anxiety Scale (SCAS) in the following domains: generalised anxiety, separation anxiety, social phobia, panic-agarophobic, obsessive-compulsive and phobia of physical injury with normative data in a European population. The study explores the associations between different DSM IV types of anxiety in children with CFS/ME at different ages and gender and investigates the association of anxiety with patient characteristics, such as age and sex and markers of severity such as fatigue and physical function.

\section{Methods}

Population

The Bath specialist paediatric CFS/ME service covers a region in the South West of England with a population of over 400,000 children aged 5-19 (2001 Census data). Children are referred from paediatric services, general practices and from schools. The service also offers assessment and treatment to children from out of the region who cannot access specialist services. Data were prospectively collected on all children assessed by the service between March 2004 and December 2007, who were between the ages of 7 and 17 at the time of the assessment and were given a clinical diagnosis of CFS/ME using the RCPCH definition for CFS/ME [21].

Inventories

The following self-completed inventories were collected before assessment:

The SCAS [24] was initially used for children aged 13 and under in the first 2 years of the service. It was extended to all children and young people seen. The SCAS is a wellvalidated inventory that measures specific DSM IV defined anxiety disorders in children. It is a 44-item self-report measure (with 6 positive filler questions) that measures the frequency of anxiety symptoms experienced by the child in the following domains: generalised anxiety, separation anxiety, social phobia, panic-agarophobic, obsessivecompulsive (OCD) and phobia of physical injury [24]. Each question is scored as "never" (0), "sometimes" (1), "often" (2) and "always" (3). The SCAS was developed originally for use in 8-12-year-old, but has subsequently been validated in children and young people up to 19 years of age [15]. As well as having high internal consistency and test-retest reliability [25], the SCAS has been used on large population samples in Australia [24], Holland [15] Germany, Japan [8], and Greece [14] to produce normative data for both total anxiety, and specific anxiety symptoms stratified according to age and sex.

The 11 question Chalder fatigue scale [2] was scored using the 0-3 method for scoring each question ( 0 for "less than usual", 1 "no more than usual" and 2 for "more than usual", and 3 for "much more than usual").

The physical function subscale of the Short-Form General Health Survey (SF-36) [11] is a widely used to assess the physical function. It consists of 10 questions and children scored between 1 ("yes limited a lot") and 3 ("no not limited at all") so that children with the most disability scored 10 whilst those with least disability scored 30 . Inventories were coded as missing if $>1$ question was missing, apart from the total SCAS, which was coded as missing when there were $>2$ missing items. For the subscale analysis, scores were coded as missing if there were $>1$ missing item. Questions for which two answers were given were coded as missing. Total scores were corrected for the number of missing items.

Pain was measured using a visual analogue scale. Time to clinical assessment was calculated as time from symptom onset to assessment in the specialist clinic. Time at school was measured using a single self-completed questionnaire on time at school over the last term.

Statistical analysis

Standard two-tailed statistical tests were used throughout; unpaired Student's $t$ tests were used to compare the means of two groups and Chi-squared tests to compare proportions.

The total anxiety score and scores for each anxiety subscale were assessed separately for boys and girls within two age bands, 7-12 and 13-17 years, as a large European study had provided normative data for each of these four subscales with cut offs for each subscale corresponding to the upper 10th centile [15]. Proportions of the CFS/ME 
children with anxiety scores above these cut-off levels were calculated and were compared with expected proportions $(10 \%)$ using one sample binomial tests. Given the large number of tests used, only a $P$ value of $<0.001$ was regarded as being statistically significant for the binomial testing.

Linear regression analyses were used to investigate the relationships between SCAS and clinic latency, disability, fatigue, pain, age, and sex, with these 'predictors' of SCAS considered individually and together. So that regression coefficients for the different inventories were comparable, they were rescaled so that the range for each was approximately 10 . Thus, the SF36 was divided by 2, SCAS anxiety and pain were divided by 10 and fatigue was divided by 3 . All analyses were restricted to children with no missing data in any of the variables investigated. All analyses were performed using Stata 9.2.

The local Research and Ethics committee decided that the collection and analysis of this data were service evaluation and as such did not require ethical review by a NHS Research Ethics Committee or approval from the NHS R\&D office (07/Q2006/48).

\section{Results}

Between March 2004 and December 2007, a total of 251 children and young people between 7 and 17 years of age were given a diagnosis of CFS/ME. Of these, $41 \mathrm{did}$ not fill in any preassessment questionnaires and were excluded from subsequent analysis. Of the remaining 210, there were $164(78.1 \%)$ who provided complete data for SCAS (no more than 2 items missing). Only the 164 children with complete data for the SCAS were included in the analysis. The median age of these children was 14.2 years (IQR $12.5,15.7)$ and only $54(32.9 \%)$ were male. The children and young people had a mean score of 29.7 for the total SCAS (range 0-85, possible range 0-114); 19.8 (SD 5.2) on the physical function inventory and 23.9 (SD 5.5) on the 11 item Chalder fatigue.
Table 1 compares patient characteristics (gender, age, disability, and fatigue) between children with and without completed SCAS. No significant differences were found between the two groups in terms of gender, disability, or fatigue. Those with a completed SCAS measure were slightly younger, reflecting the development of the CFS/ ME service. In the first year of the study, the SCAS was used only for younger children, before being extended to all children in the second year.

Relationship between total anxiety and patient characteristics

One hundred and fifty-three children had a completed SCAS as well as the Chalder fatigue score, physical function (SF 36), pain (visual analogue scale), age, gender, and time to assessment. In this group, there was no evidence of an association between total anxiety score and either time to clinic assessment (regression coefficient $-0.04,95 \%$ CI $-0.17,0.1)$, pain $(0.07,95 \%$ CI -0.04 , $0.182)$ or time at school $(-0.04,95 \%$ CI $-1.4,1.3)$. The total anxiety level was related to the level of fatigue, although this relationship was attenuated when adjusted for age, gender, and disability (Table 2). There also appeared to be a weak relationship with physical function, but this disappeared after adjustment for the other factors in a multivariable analysis (Table 2). Although total anxiety was strongly associated with gender, it was not related to age.

Comparison of total anxiety and anxiety subtypes with a European community sample

The data on children with CFS/ME were compared with normative data from a large Dutch study of 1,011 children where cut-off scores (top 10\%) had been identified by age and gender [15] (Table 3). Teenage girls (13-17) were most likely to have a problem with total anxiety as $38 \%$ of teenage girls with fatigue had scores about the $10 \%$ cut off. A significantly higher proportion of girls in this age scored above

Table 1 Characteristics of children and young people at assessment comparing those with and without completed SCAS using Students $t$ test

\begin{tabular}{|c|c|c|c|c|c|c|}
\hline & \multicolumn{2}{|c|}{ With SCAS } & \multicolumn{2}{|c|}{ Without SCAS } & \multirow[t]{2}{*}{ Mean difference $(95 \% \mathrm{CI})$} & \multirow[t]{2}{*}{$P$ value $^{\mathrm{a}}$} \\
\hline & $N$ & & $N$ & & & \\
\hline Age in years: median (IQR) & 164 & $14.2(12.5,15.7)$ & 46 & $16.0(14.8,17.2)$ & $-1.8(-2.5,-1.0)$ & $<0.001$ \\
\hline Male frequency $(\%)$ & 164 & $54(32.9)$ & 46 & $11(23.9)$ & & $0.24^{\mathrm{b}}$ \\
\hline SF36: mean (SD) & 159 & $19.8(5.2)$ & 42 & $19.6(4.3)$ & $0.15(-1.6,1.9)$ & 0.87 \\
\hline Fatigue mean (SD) & 158 & $23.9(5.5)$ & 39 & $24.7(7)$ & $0.86(-2.9 .1 .2)$ & 0.40 \\
\hline
\end{tabular}

a Students $t$ test

b Chi-squared test 
Table 2 Regression coefficients (95\% confidence intervals) for the relationships between total anxiety (SCAS) and disability (SF36), fatigue, age, and gender $(n=153)$

\begin{tabular}{|c|c|c|c|c|}
\hline & \multicolumn{2}{|l|}{ Univariable analyses } & \multicolumn{2}{|l|}{ Multivariable analyses } \\
\hline & Coefficient $(95 \% \mathrm{CI})$ & $P$ value & Coefficient $(95 \% \mathrm{CI})^{*}$ & $P$ value \\
\hline Physical function & $-0.14(-0.26,-0.02)$ & 0.025 & $-0.06(-0.2,0.08)$ & 0.406 \\
\hline Fatigue & $0.28(0.11,0.46)$ & 0.001 & $0.22(0.02,0.41)$ & 0.031 \\
\hline Gender $^{\mathrm{a}}$ & $1.24(0.58,1.89)$ & $<0.001$ & $1.24(0.58,1.9)$ & $<0.001$ \\
\hline Age (years) & $0.02(-0.13,0.16)$ & 0.834 & $-0.05(-0.19,0.09)$ & 0.457 \\
\hline
\end{tabular}

a The association is with female sex

the cut off for each anxiety subscale (apart from the physical injury) when compared with the normal population.

Girls in the younger age group (age 7-12) also scored highly with three times the number of children scoring above the 10th centile cut off. They also appeared to be particularly likely to have problems in the separation (37\%) and social phobia (39\%) subscales. Anxiety in boys was generally less marked, particularly in the 13-17-year-old group where in many domains (OCD, separation and physical injury scales) anxiety did not differ significantly from the normal population controls.

\section{Discussion}

This study presents data from a large cohort of children with CFS/ME, which allowed analysis according to the gender, age, and anxiety subtype. Girls with CFS/ME reported significantly higher levels of anxiety then boys. When compared with a community sample, 3-4 times as many girls with CFS/ME scored above the 10th centile cut off. In older girls, this was true not only for total anxiety, but also for all anxiety subscales apart from fear of physical injury. Younger girls are more likely to experience problems with separation anxiety and social phobia compared with normative controls.

Total anxiety was not associated with age, but was strongly associated with gender and moderately associated with fatigue. As this is not a longitudinal study, we do not know the direction of causality of this association. We had hypothesised that anxiety would correlate with disability, school attendance and/or time to diagnosis but this assumption was not proven.

Separation anxiety and social phobia appeared to be the anxiety subscales most likely to have a high proportion of children scoring above the cut-off level, particularly girls of all ages. A tendency for separation anxiety and social phobia to be over-represented in girls has been noted [7]. Similarly, developmental variations in the presence of these disorders have been reported with separation anxiety tending to decrease with age, whereas social phobia increases [22]. However within this CFS/ME group, reported symptoms associated with social phobia and separation anxiety were similarly high in girls of all ages. In some respects, this finding is not surprising. During their illness, the child will inevitably have become increasingly dependent on their carers that may result in the development of worries about separation. Similarly, social phobia is concerned with a fear of negative evaluation. Integrating with a friendship group and performing in class is already difficult for many children, but with long absences, high levels of fatigue and the memory and attentional problems associated with CFS/ME, concerns about social performance may be particularly strong for this group. Further studies are needed to understand more about the development of anxiety symptoms in this group.

The implications of these symptoms in terms of impairing the child's ability to independently function within school and social contexts could present children with CFS/ME with further problems that might hinder their recovery and ability to re-engage with everyday life. Clinically, this raises the important question about treatment and the need to assess and intervene with significant anxiety symptoms with the CFS/ME population that might interfere with their recovery. Whether specifically addressing comorbid anxiety symptoms might enhance the effectiveness of these interventions would appear a useful avenue for future research.

\section{Strengths and weaknesses of this study}

This is the first study to look in detail at anxiety symptoms in a large number of children with CFS/ME. The large sample size has enabled us to look both at different DSM IV types of anxiety and also at anxiety in children of different ages and gender. As inventories were completed by the young person before the assessment, the anxiety symptoms are unlikely to be due to the hospital setting. However, the study does have a number of limitations. First, the control group was not from the UK thereby raising the possibility that this group is not representative of children in the UK. However, the Dutch group was 
Table 3 Comparison of anxiety scores according to age and gender with cut-off scores described by Muris et al. [15] defining the 90th centile (top $10 \%$ ) of the normal population

\begin{tabular}{|c|c|c|c|c|c|c|}
\hline & \multirow[t]{2}{*}{$N$} & \multirow[t]{2}{*}{ Mean (SD) } & \multicolumn{4}{|c|}{ Comparison with normal population } \\
\hline & & & Cut-off score & $\begin{array}{l}\text { Number }>90 \text { th } \\
\text { centile }\end{array}$ & $\begin{array}{l}\text { Percentage of }(95 \% \mathrm{CI}) \\
\text { exceeding } 90 \text { th centile }^{\mathrm{a}}\end{array}$ & $P$ \\
\hline \multicolumn{7}{|c|}{ Total anxiety score } \\
\hline Boys aged $<13$ & 22 & $22.8(14.8)$ & 37 & 5 & $23(8-45)$ & 0.06 \\
\hline Girls aged $<13$ & 30 & $36.2(19.5)$ & 44 & 9 & $30(15-49)$ & 0.002 \\
\hline Boys aged $\geq 13$ & 32 & $21.1(17.2)$ & 25 & 5 & $16(5-33)$ & 0.25 \\
\hline Girls aged $\geq 13$ & 80 & $32.7(20.9)$ & 36 & 30 & $38(27-49)$ & $<0.001$ \\
\hline \multicolumn{7}{|c|}{ Generalised anxiety } \\
\hline Boys aged $<13$ & 23 & $4.5(3)$ & 8 & 2 & $9(11-28)$ & $>0.99$ \\
\hline Girls aged $<13$ & 31 & $7.3(3.9)$ & 9 & 8 & $26(12-45)$ & 0.009 \\
\hline Boys aged $\geq 13$ & 32 & $4.9(4)$ & 6 & 6 & $19(7-36)$ & 0.13 \\
\hline Girls aged $\geq 13$ & 81 & $6.9(4.3)$ & 9 & 22 & $27(18-38)$ & 0.001 \\
\hline \multicolumn{7}{|l|}{ Separation anxiety } \\
\hline Boys aged $<13$ & 23 & $5.4(3.3)$ & 7 & 7 & $30(13-53)$ & 0.006 \\
\hline Girls aged $<13$ & 30 & $6.6(4.4)$ & 8 & 11 & $37(20-56)$ & $<0.001$ \\
\hline Boys aged $\geq 13$ & 32 & $2.3(3.1)$ & 4 & 4 & $13(4-29)$ & 0.55 \\
\hline Girls aged $\geq 13$ & 81 & $4.4(4)$ & 5 & 23 & $28(19-40)$ & $<0.001$ \\
\hline \multicolumn{7}{|l|}{ Social phobia } \\
\hline Boys aged $<13$ & 22 & $5(3.8)$ & 6 & 6 & $27(11-50)$ & 0.018 \\
\hline Girls aged $<13$ & 31 & $7.3(4.8)$ & 8 & 12 & $39(22-58)$ & $<0.001$ \\
\hline Boys aged $\geq 13$ & 32 & $5.3(3.2)$ & 6 & 7 & $22(9-40)$ & 0.036 \\
\hline Girls aged $\geq 13$ & 80 & $7.6(4.3)$ & 8 & 28 & $35(25-47)$ & $<0.001$ \\
\hline \multicolumn{7}{|l|}{ Panic-agarophobic } \\
\hline Boys aged $<13$ & 22 & $3.4(3.2)$ & 6 & 5 & $23(8-45)$ & 0.06 \\
\hline Girls aged $<13$ & 30 & $5.1(3.8)$ & 8 & 4 & $13(4-31)$ & 0.54 \\
\hline Boys aged $\geq 13$ & 32 & $3.0(3.9)$ & 4 & 6 & $19(7-36)$ & 0.13 \\
\hline Girls aged $\geq 13$ & 80 & $5.9(5.3)$ & 6 & 29 & $36(26-48)$ & $<0.001$ \\
\hline \multicolumn{7}{|c|}{ Obsessive-compulsive } \\
\hline Boys aged $<13$ & 22 & $1.8(2.0)$ & 7 & 0 & $0(0-15)^{*}$ & 0.16 \\
\hline Girls aged $<13$ & 31 & $4.4(3.9)$ & 7 & 7 & $23(10-41)$ & 0.03 \\
\hline Boys aged $\geq 13$ & 32 & $3.0(3.9)$ & 5 & 4 & $13(4-29)$ & 0.56 \\
\hline Girls aged $\geq 13$ & 79 & $3.9(4)$ & 6 & 20 & $25(16-36)$ & $<0.001$ \\
\hline \multicolumn{7}{|c|}{ Physical injury fears } \\
\hline Boys aged $<13$ & 22 & $2.9(2.4)$ & 5 & 3 & $14(3-35)$ & 0.48 \\
\hline Girls aged $<13$ & 31 & $5.2(2.6)$ & 7 & 5 & $16(5-34)$ & 0.23 \\
\hline Boys aged $\geq 13$ & 32 & $2.5(2.4)$ & 5 & 2 & $6(8-21)$ & 0.77 \\
\hline Girls aged $\geq 13$ & 80 & $4.1(2.9)$ & 6 & 16 & $20(12-30)$ & 0.007 \\
\hline
\end{tabular}

${ }^{a}$ From comparison with expected proportion using one sample binomial test

chosen for comparison because it covered the right age range and because it was thought to be closest in terms of ethnic mix to the predominantly white population of Bath and Bristol. The results between the Dutch [15] and German [8] cohorts were similar in terms of overall anxiety and levels of specific anxiety symptoms.

Secondly, the sample of children in this study was referred to a specialist service and it is unclear whether these results are generalisable to the wider CFS/ME population.
Although children may be referred to a specialist service because they are more anxious, studies suggest that children with CFS/ME seen in non-specialist settings also present with high levels of mental health difficulties, particularly emotional problems [19]. Further larger studies need to be undertaken to explore levels of anxiety in children with CFS/ME in primary and secondary care.

Thirdly, this study has relied upon self-completed questionnaires. Whilst this has highlighted that anxiety 
symptoms within this population are high the clinical significance of these findings is unclear. Diagnostic interviews were not undertaken to substantiate diagnostic criteria and to, therefore, identify rates of anxiety disorders. In addition, there is a considerable comorbidity between anxiety disorders and depression and in the absence of any diagnostic interviews; it is not possible to identify the extent of comorbidity or the nature of the primary disorder. Future studies should address this shortfall using diagnostic interviews to both quantify the number of children with CFS/ME who fulfil diagnostic criteria for an anxiety disorder and identify children with other comorbid disorders.

Comparison with previous studies investigating anxiety in $\mathrm{CFS} / \mathrm{ME}$

Previous studies have also shown that children with CFS/ ME have high levels of anxiety compared with normative controls and compared with children with other long-term conditions, such as juvenile idiopathic arthritis and migraine $[10,18,23]$. However, these studies had a smaller sample size and were unable to look at the different types of anxiety stratified according to age and gender. Our study used a community sample as a control group and, therefore, we are unable to determine whether the increased symptoms described are specific to CFS/ME or are common to longterm conditions in general. In addition, the number of children with levels of anxiety over the cut off in our study is lower than some previous studies, but this could be explained by the large sample size and differences in the way that anxiety has been assessed. This study did not attempt to and indeed cannot make any assumptions about direction of causality and this will need to be examined in longitudinal cohorts. There is some retrospective evidence that there is an increased risk of anxiety prior to the development of CFS/ME, but as mean disease duration was 19 months and the sample size was small (36 girls) it is difficult to draw conclusions [26]. A large UK cross-sectional study demonstrated a high association of anxiety with $\mathrm{CFS} / \mathrm{ME}$ and a higher risk of developing chronic fatigue at time 4-6 months later [20]. However, it is also plausible that the associated anxiety is because CFS/ME predisposes young people to developing psychological problems. This is consistent with the only longitudinal study to date which reported that maternal psychopathology, childhood, or adolescent psychological distress are not associated with the risk of lifetime self-reported CFS/ME [27].

\section{Conclusion}

This study has demonstrated that anxiety symptoms as assessed by the well-validated SCAS appear to be increased in all groups of children with CFS/ME. High levels of total anxiety appear to be a particular problem for girls. In teenage girls this is true not only for total anxiety, but also for the anxiety subscales apart from physical injury whilst younger girls' anxiety symptoms appear more likely to be restricted to separation anxiety and social phobia. Anxiety does not appear to be associated with time at school, time to assessment, pain, physical function, or age although there was a moderate association with fatigue.

Acknowledgments Thanks to the Linbury Trust for funding part of Dr Crawley's salary, Mr Andrew Haig-Ferguson who was involved in data management and to the children and young people who were part of this study.

\section{References}

1. Carter BD, Kronenberger WG, Edwards JF et al (1999) Psychological symptoms in chronic fatigue and juvenile rheumatoid arthritis. Pediatrics 103:975-979

2. Chalder T, Berelowitz G, Pawlikowska T et al (1993) Development of a fatigue scale. J Psychosom Res 37:147-153

3. Chalder T, Goodman R, Wessely S et al (2003) Epidemiology of chronic fatigue syndrome and self reported myalgic encephalomyelitis in 5-15 year olds: cross sectional study. Br Med J 327:654-655

4. Costello EJ, Mustillo S, Erkanli A et al (2003) Prevalence and development of psychiatric disorders in childhood and adolescence. Arch Gen Psychiatry 60:837-844

5. Dowsett EG, Colby J (1997) Long-term sickness absence due to ME/CFS in UK schools: an epidemiological study with medical and educational implications. J Chronic Fatigue Syndr 3:29-42

6. Garralda E, Chalder T (2005) Practitioner review: chronic fatigue syndrome in childhood. J Child Psychol Psychiatry. 46:11431151

7. Essau CA, Conradt J, Petermann F (2000) Frequency, comorbidity, and psychosocial impairment of anxiety disorders in German adolescents. J Anxiety Disord 14:263-279

8. Essau CA, Sakano Y, Ishikawa S et al (2004) Anxiety symptoms in Japanese and in German children. Behav Res Ther 42:601-612

9. Farmer A, Fowler T, Scourfield J et al (2004) Prevalence of chronic disabling fatigue in children and adolescents. Br J Psychiatry 184:477-481

10. Garralda E, Rangel L, Levin M et al (1999) Psychiatric adjustment in adolescents with a history of chronic fatigue syndrome. J Am Acad Child Adolesc Psychiatry 38:1515-1521

11. Garratt AM, Ruta DA, Abdalla MI et al (1993) The Sf-36 health survey questionnaire: an outcome measure suitable for routine use within the NHS. Br Med J 306:1440-1444

12. Jones JF, Nisenbaum R, Solomon L et al (2004) Chronic fatigue syndrome and other fatiguing illnesses in adolescents: a population-based study. J Adolesc Health 35:34-40

13. Jordan KM, Ayers PM, Jahn SC et al (2000) Prevalence of fatigue and chronic fatigue syndrome-like illness in children and adolescents. J Chronic Fatigue Syndr 6:3-21

14. Mellon RC, Moutavelis AG (2007) Structure, developmental course, and correlates of children's anxiety disorder-related behavior in a Hellenic community sample. J Anxiety Disord 21:1-21

15. Muris $P$, Schmidt H, Merckelbach H (2000) Correlations among two self-report questionnaires for measuring DSM-defined anxiety disorder symptoms in children: the Screen for Child Anxiety 
Related Emotional Disorders and the Spence Children's Anxiety Scale. Pers Individ Dif 28:333-346

16. National Institute for Health and Clinical Excellence (NICE) (2007) Chronic fatigue syndrome/myalgic encephalomyelitis (or encephalopathy); diagnosis and management, CG53

17. Patel MX, Smith DG, Chalder T et al (2003) Chronic fatigue syndrome in children: a cross sectional survey. Arch Dis Child 88:894-898

18. Rangel L, Garralda ME, Hall A et al (2003) Psychiatric adjustment in chronic fatigue syndrome of childhood and in juvenile idiopathic arthritis. Psychol Med 33:289-297

19. Richards J, Turk J, White S (2005) Children and adolescents with chronic fatigue syndrome in non-specialist settings: beliefs, functional impairment and psychiatric disturbance. Eur Child Adolesc Psychiatry 14:310-318

20. Rimes KA, Goodman R, Hotopf $M$ et al (2007) Incidence, prognosis, and risk factors for fatigue and chronic fatigue syndrome in adolescents: a prospective community study. Pediatrics 119:e603-e609

21. Royal College of Paediatrics and Child Health (2004) Evidence based guideline for the management of CFS/ME (Chronic Fatigue
Syndrome/Myalgic Encephalopathy) in Children and Young People, 2004, London

22. Silverman WK (2004) Separation anxiety disorder. In: Morris TL, March JS (eds) Anxiety disorders in children and adolescents. The Guilford Press, New York

23. Smith MS, Martin-Herz SP, Womack WM et al (2003) Comparative study of anxiety, depression, somatization, functional disability, and illness attribution in adolescents with chronic fatigue or migraine. Pediatrics 111:e376-e381

24. Spence SH (1998) A measure of anxiety symptoms among children. Behav Res Ther 36:545-566

25. Spence SH, Barrett PM, Turner CM (2003) Psychometric properties of the Spence Children's Anxiety Scale with young adolescents. J Anxiety Disord 17:605-625

26. Van Middendorp H, Geenen R, Kuis W et al (2001) Psychological adjustment of adolescent girls with chronic fatigue syndrome. Pediatrics 107:E35

27. Viner R, Hotopf M (2004) Childhood predictors of self reported chronic fatigue syndrome/myalgic encephalomyelitis in adults: national birth cohort study. Br Med J 329:941 